COMMENT. A consensus view of Panayiotopoulos syndrome (PS) determined by an international consortium concludes that PS is a common idiopathic, benign seizure disorder of childhood that should be classified as an autonomic epilepsy, rather than an occipital epilepsy (Ferrie C et al. Dev Med Child Neurol 2006 Mar;48(3):236-40). Recognized by the ILAE as a distinct clinical entity within the spectrum of benign focal epilepsies of childhood, PS is manifested electrographically with multiple interictal spikes (Kokkinos V et al. Clin Neurophysiol 2010 Jun;121(6):859-69).

Autonomic epilepsy is frequently misdiagnosed and treated as atypical migraine, syncope, or abdominal disorder, leading to unnecessary and sometimes invasive investigations. The present UK study of PS concludes that in atypical cases of suspected syncope in children having focal spikes in the EEG, a diagnosis of syncope-like epileptic seizures in PS should be considered.

\title{
DEVELOPMENTAL \& AUTISM SCREENING IN EPILEPSY UNIT
}

Researchers at the Epilepsy Center, Ann \& Robert H Lurie Children's Hospital of Chicago assessed the yield of routine screening for neurodevelopmental delay and autism in all patients, 5 years of age and younger, seen in the monitoring unit or ketogenic diet clinic. The Ages and Stages Questionnaire, a parent completed form selected for development screening, addresses communication, gross and fine motor, problem solving, and personal-social. The Modified Checklist for Autism in Toddlers (mCHAT) was used for children up to age 4 years; and the Social Communication Questionnaire (SCQ) in children 4 years and older. Of 65 who participated, 49 (75\%) were established epilepsy patients, and $16(25 \%)$ were screened in a new-onset epilepsy clinic. Mean age at screening was 2.5 years (range 2 months to 5 years), and $38(58 \%)$ were boys. Seizure frequency at time of screening was seizure free $(\mathrm{N}=14),<1$ /month $(\mathrm{N}=2)$, monthly $(\mathrm{N}=4)$, weekly $(\mathrm{N}=5)$, and daily $(\mathrm{N}=30)$.

Developmental screening was positive/delayed in $47(72 \%)$, negative in $10(15 \%)$, and borderline in $8(12 \%)$. Established epilepsy patients were more likely to be developmentally delayed and to test positive than new-onset patients $(p=0.0001)$. Among 49 screened for autism, $24(49 \%)$ scored positive. Of 12 with normal or borderline developmental screening, none screened positive for autism, whereas 24 of $37(65 \%)$ of those with developmental delay also scored positive for autism $(p<0.0001)$. The prevalence of positive autism screening correlated with the degree and type of developmental delay. Delays in the social-personal domain were more likely than those in gross and fine motor to discriminate between positive and negative autism screening. Positive autism screening in 20 children were better explained by the underlying developmental delays. New concerns identified through screening prompted referrals for further evaluations in 16 patients; these included physical therapy, speech therapy, early intervention mental health and school services, and psychiatry. The yield of routine screening was sufficiently high to support developmental and autism screening in all children attending an epilepsy center. (Fisher B, Dezort C, Nordli DR, Berg AT. Routine developmental and autism screening in an epilepsy care setting. Epilepsy Behav 2012 Aug;24(4):488-92). (Respond: Dr Anne T Berg. E-mail: atberg@luriechildrens.org).

COMMENT. The authors conclude that comorbid developmental and behavioral 
problems in children with epilepsy are sufficiently prevalent to warrant routine screening. The screening program in the Epilepsy Center at the Lurie Children's Hospital of Chicago has been expanded to include patients up to 18 years of age. The American Academy of Pediatrics recommends routine developmental and autism screening for all infants and toddlers. (AAP. Pediatrics 2001 Jul;108(1):192-6) (Filipek PA et al. Neurology 2000 Aug 22;55(4):468-79).

\section{GAIT DETERIORATION IN ADOLESCENTS WITH DRAVET SYNDROME}

Researchers at the University of Melbourne, Australia studied prospectively changes in gait by age in patients with Dravet syndrome. Of 26 patients aged 2 to 34 years, 15 were male and 11 female, mean age 11.6 years; 23 had SCN1A mutations. Children aged 0 to 5 years $(\mathrm{N}=7)$ had a normal gait, whereas 5 of 10 aged 6 to 12 years and 8 of 9 children aged 13 years or older had crouch gait. Ataxia was rarely observed in this cohort. Crouch gait is characterized by increased hip and knee flexion and ankle dorsiflexion, weakness in antigravity lower limb muscles, and without hypertonia or spastic cerebral palsy. Physical examination showed with increasing age, a decrease in passive knee extension and hip extension, and an increase in external tibial torsion and pes planovalgus. Increase in hip internal rotation showed no age-related change. The Functional Mobility Scale showed universal independent walking over 5 and $50 \mathrm{~m}$, whereas adolescents and adults showed wide variation in ratings over $500 \mathrm{~m}$, wheelchair use to independent walking. (Rodda JM, Scheffer IE, McMahon JM, Berrkovic SF, Graham HK. Progressive gait deterioration in adolescents with Dravet syndrome. Arch Neurol 2012 Jul;69(7):873-8). (Respond: Ingrid E Scheffer PhD, MBBS, Florey Neuroscience Institutes, Melbourne Brain Centre, 245 Burgundy Rd, Heidelberg, Melbourne, Victoria 3084, Australia. E-mail: scheffer@unimelb.edu.au).

COMMENT. Some reports estimate that $50 \%$ to $60 \%$ of Dravet syndrome patients have an ataxic gait (Korff C, Laux L, Kelley K, Goldstein J, Koh S, Nordli D Jr. J Child Neurol 2007 Feb;22(2):185-94). The cause of crouch gait in adolescents with Dravet syndrome in the present study is unclear, and the typical gait abnormality usually referred to as ataxic or spastic was absent. The authors speculate a possible relation to joint problems and planus foot deformity as precursors, and discuss the pros and cons of orthotic and surgical management. The impact of seizures, type of mutation, and anticonvulsants on the development of crouch gait are also suspect. Development of some connective tissue disorders (Dupuytren's contracture, general joint pain) is linked to treatment with anticonvulsant drugs, especially phenobarbital. (Mattson RH, Cramer JA, McCutchen CB. Arch Intern Med 1989 Apr;149(4):911-4).

\section{MRI ABNORMALITIES WITH FEBRILE STATUS EPILEPTICUS: THE FEBSTAT STUDY}

Researchers in the FEBSTAT Study Team at centers in New York, Durham, Virginia, and Chicago, IL report MRI findings in their prospective study of the acute effects of febrile status epilepticus (FSE) in 199 children age 1 month to 5 years. Patients 